\title{
Maternal and perinatal outcome in eclampsia complicated by posterior reversible encephalopathy syndrome; a three years' experience in a tertiary care hospital
}

\author{
Shashikala Karanth ${ }^{1}$, Kavitha Gonsalves ${ }^{1}$, Sheela C. N. ${ }^{1 *}$, Reena Mathew ${ }^{1}$, G. R. K. Sarma ${ }^{2}$, \\ Babu Phillip ${ }^{3}$, Sumithra ${ }^{4}$
}

${ }^{1}$ Department of Obstetrics and Gynecology, ${ }^{2}$ Department of Neurology, ${ }^{3}$ Department of Radiology, ${ }^{4}$ Department of Biostatistics, St. Johns Medical College and Hospital, Bengaluru, Karnataka, India

Received: 29 August 2017

Accepted: 25 September 2017

*Correspondence:

Dr. Sheela C. N.,

E-mail: drsheela1960@gmail.com

Copyright: (c) the author(s), publisher and licensee Medip Academy. This is an open-access article distributed under the terms of the Creative Commons Attribution Non-Commercial License, which permits unrestricted non-commercial use, distribution, and reproduction in any medium, provided the original work is properly cited.

\begin{abstract}
Background: PRES can be associated with number of medical conditions and was observed frequently in patients with preeclampsia and eclampsia. Neuroimaging is important for the diagnosis of PRES. Study was conducted to find out the maternal and perinatal outcome in patients with eclampsia complicated by posterior reversible encephalopathy syndrome (PRES).

Methods: This is a retrospective study done at St. Johns Medical College Bangalore, between October 2013 and October 2016. We reviewed case records of all the patients with eclampsia who underwent neuro imaging studies and a diagnosis of PRES was made. The maternal and perinatal outcomes in these women were studied

Results: In the past three years we had 55 cases of eclampsia who underwent neuroimaging studies for persistent neurological symptoms after 24 hours of $\mathrm{MgSO}_{4}$ treatment. Of these women 30 were diagnosed to have PRES. In the present study PRES was common in multiparous women and more in patients with antepartum eclamptic women. Mean age at diagnosis of PRES was $26 \pm 5.1$ years. Common presenting symptoms were headache (93.3\%) and vomiting (53.3\%). The mean SBP/DBP was $180 / 110 \mathrm{mmHg}$. All patients who had recurrent seizures were controlled with $\mathrm{MgSO}_{4}$ alone. $53.3 \%$ of our patients had eclampsia related complications and $36.7 \%$ required ICU care. There were 3 maternal deaths (10\%). Perinatal mortality was $20 \%$.

Conclusions: Neuroimaging in eclamptic patients with persistent neurological symptoms could help in early diagnosis of PRES and multidisciplinary approach in management could contribute significantly in reducing the maternal mortality and morbidity.
\end{abstract}

Keywords: Eclampsia, $\mathrm{MgSO}_{4}, \mathrm{MRI} / \mathrm{CT}$, PRES

\section{INTRODUCTION}

Posterior reversible encephalopathy syndrome (PRES) is a clinical-neuroradiological entity, was first described in 1996 by Hinchey et al. This syndrome is characterized by headache, visual disturbances, seizures, altered mental status and radiological findings of oedema in the white matter of the brain on MRI. ${ }^{1,2,4}$ PRES can clinically associated with number of medical conditions such as hypertensive encephalopathy, preeclampsia, eclampsia, acute renal diseases, haemolytic uremic syndrome, use of cytotoxic and immunosuppressant drugs. ${ }^{3}$ Recent studies and previous case reports states that PRES was observed frequently in patients with preeclampsia and eclampsia. ${ }^{5}$ Although pathophysiology of PRES is poorly understood, the same pathophysiological mechanisms of eclampsia 
are shared. ${ }^{6}$ Neuroimaging is important for the diagnosis of PRES and radiological abnormalities are best demonstrated by magnetic resonance imaging. ${ }^{1}$ Prompt recognition and treatment with the support of a multidisciplinary team are crucial to avoid the permanent neuronal damage and reduce the maternal mortality. Data regarding the outcome of eclamptic women suffering from posterior encephalopathy syndrome (PRES) sparse in the literature. Many are case reports with very few prospective/retrospective studies with limited sample size. ${ }^{3}$ Junewar et al conducted a prospective observational study, to study the predictors of posterior encephalopathy syndrome, but the sample size of the study was small. ${ }^{7,8}$ The purpose of this study was to study the maternal and foetal outcome and associated complications in patients with eclampsia with PRES. ${ }^{4}$

\section{METHODS}

Retrospective chart review of all cases of eclampsia complicated with PRES treated at St Johns Medical College and Hospital between October 2013 to September 2016 was carried out. The study was approved by the institutional ethics committee. All eclamptic women with neurological symptoms (who had persistent headache or visual disturbances even after 24 hours of $\mathrm{MgSO}_{4}$ ), who underwent neuroimaging study were included in the study. The pregnant women with eclampsia occurring after 20 weeks of gestation or within 6 weeks of the postpartum period were included. The patients with past history of neurological disorders were excluded. Posterior encephalopathy syndrome was defined as the occurrence of neurological syndrome consisting of headache, seizure, visual disturbance or focal deficit along with characteristic brain imaging findings localized mainly to the posterior regions of the brain. Diagnosis of PRES was made using one or more imaging modalities including MRI with or without contrast, CT with or without contrast. The clinical features, radiological features, associated complications, maternal outcome were studied. The perinatal outcomes including birth weight, gestational age at birth, APGAR scores, still birth, admission to neonatal intensive care unit, were studied.

\section{Statistical methods}

Descriptive statistics was reported using mean and standard deviation, median with interquartile ranges for the continuous variables. Number and percentages for the categorical variables. Square test was used to test the association between mortality and clinical variables. $\mathrm{P}$ value less than 5\% was considered statistically significant. Statistical analyses were carried out using SPSS software version 21 .

\section{RESULTS}

A total of 7772 patients delivered between October 2013 to September 2016. Of these, 55 women were presented with eclampsia and 30 of them underwent CT/MRI for persistent neurological symptoms. The incidence of PRES was $0.4 \%$, in the current study. Among 30 women who had persistent neurological symptoms, 22 women had antepartum eclampsia and 8 women had eclampsia in postpartum period. The mean age of the women at diagnosis of PRES was 26 \pm 5.1 years (range, 22-30 years). Most of them delivered preterm (27 out of 30 ). The median gestational age at delivery was 34 (31-36) weeks. In the present study, 17 (57\%) patients were delivered by caesarean sections 13 (43\%) patients delivered vaginally. The demographic and clinical characteristics are summarised in (Table 1).

Table 1: Clinical and demographic characteristics of the study subjects.

\begin{tabular}{|lll|}
\hline Clinical variables & No. $(\mathrm{n}=30)$ & Percentage \\
\hline Multi parity & 19 & 63 \\
\hline Pre-term & 28 & 93.3 \\
\hline $\begin{array}{l}\text { Persistent impending } \\
\text { symptoms }\end{array}$ & 30 & 100 \\
\hline $\begin{array}{l}\text { Antepartum >postpartum } \\
\text { Complications (DIC, HELL } \\
\text { pulmonary oedema) }\end{array}$ & 22 & 73.3 \\
\hline ICU care & 16 & 53.3 \\
\hline Induction of labour & 11 & 36.7 \\
\hline LSCS & 17 & 50 \\
\hline Maternal mortality & 3 & 56.7 \\
\hline Still birth & 6 & 9.9 \\
\hline Treated with $\mathrm{MgSO}_{4}$ & 30 & 20 \\
\hline
\end{tabular}

Mean systolic and diastolic blood pressures were $187 \pm 12$ and $110 \pm 6 \mathrm{~mm} \mathrm{Hg}$ respectively. The common presenting symptoms of PRES were summarised in Figure 1.

Out of 30 women with PRES 16 (53.3\%) had complications like HELLP, DIC and pulmonary oedema, whereas $11(36.7 \%)$ women required ICU care. There were $3(9.9 \%)$ maternal deaths in the current study. Radiological evidence of PRES was found in multiple sites.

Table 2: MRI/CT findings of PRES patients.

\begin{tabular}{|lll|}
\hline Report & CT/ & No. \\
Temporo parietal occipital region & CT & $9(30)$ \\
\hline Fronto parietal occipital region & CT & $15(50)$ \\
\hline Atypical PRES & MRI & $1(3.3)$ \\
\hline Cerebral Oedema & CT & $3(9.9)$ \\
\hline Intracranial bleed followed by PRES & CT/MRI & $3(9.9)$ \\
\hline
\end{tabular}

All patients except one underwent imaging within 72 hours of seizure onset; MRI abnormalities are shown in Table 2. Perinatal outcome such as gestational age at delivery, birth weight, Apgar score, NICU admission, perinatal mortality is summarized in Table 3. 
Recurrent seizures, DIC, ICU admission, pulmonary oedema and HELLP were significantly associated with the presence of mortality $(\mathrm{p}<0.01)$.

\section{Table 3: Perinatal characteristics of eclampsia} patients with PRES.

\begin{tabular}{lll} 
Characteristics & Gestational age & No. $(\%)$ \\
Post-datism & $>40$ weeks & $1(3.3)$ \\
Term & $>37$ weeks & $2(6.6)$ \\
\hline Near term & $34-36$ weeks & $12(40)$ \\
Moderate prematurity & $32-33$ weeks & $5(16.5)$ \\
Severe prematurity & $28-31$ weeks & $7(23.1)$ \\
\hline Extreme prematurity & $<28$ weeks & $3(9.9)$ \\
NICU & & $19(62.7)$ \\
\hline Perinatal mortality & & $6(19.8)$ \\
\hline APGAR (1/5) & & \\
$8 / 10,9 / 10$ & $>2.6 \mathrm{Kg}$ & 3 \\
$7 / 10,8 / 10$ & $>1.5 \mathrm{Kg}$ & 10 \\
$6 / 10,8 / 10$ & $800 \mathrm{~g}-1.5 \mathrm{Kg}$ & 6 \\
$0 / 10,0 / 10$ & & 11 \\
\hline
\end{tabular}

\section{DISCUSSION}

PRES is a rare and serious condition. It is a clinicoradiological entity characterized by altered mental status, headache, visual disturbances and seizures associated with an abrupt increase in blood pressure. Review of literatures and previous case reports reported that it also can occur without seizures in preeclamptic women. ${ }^{8}$ As the name suggest, it is reversible once underlying cause is treated. The pathophysiology behind PRES is not clearly understood and two mechanisms have been put forth, failure of auto regulation and endothelial dysfunction resulting in vasogenicoedema., Most cases of PRES in obstetrics are seen in the setting of acute hypertensive encephalopathy, preeclampsia, eclampsia or nephrotic states. ${ }^{1,9,10}$ Neuroimaging is important tool for the diagnosis of PRES and abnormalities encountered in PRES are best demonstrated by magnetic resonance imaging (MRI). ${ }^{11}$ Typical and atypical forms of PRES have been documented. ${ }^{12}$

Incidence of eclampsia in the present study is $0.7 \%$, while incidence reported from other parts of India $2.1 \%{ }^{13}$ The global incidence of PRES is unknown. Incidence of PRES in our hospital is higher $(0.4 \%)$ compared to other studies. ${ }^{9,14}$ It could be because ours is a tertiary care hospital where patients are referred from other centers and also because facilities for neuroimaging are not universally available. Incidence of PRES in eclamptic women is $54.5 \%$ in the present study as compared to $62.5 \%$ in Nelli et al study, $19.2 \%$ in Mayama study. ${ }^{14,6}$

In present study mean age of women diagnosed with PRES was $26 \pm 5.1$ years and common in multigravidas. Manavi PJ study showed that average age of PRES is 21 years, many were primigravidas. ${ }^{15}$ Study done by Shobhabembalgi, Fisher $\mathrm{N}$ et al and many case reports had reported incidence of PRES is more in postpartum period. ${ }^{9,13,16-18}$ In the present study group we observed the $73.3 \%$ and $26.7 \%$ of the patients had PRES during the antepartum and postpartum respectively and is similar to Manavi PJ study. ${ }^{15}$ A study done by Brewer $\mathrm{J}$ reported that no significant difference between incidence of PRES in antepartum or postpartum eclamptic patients. ${ }^{8}$

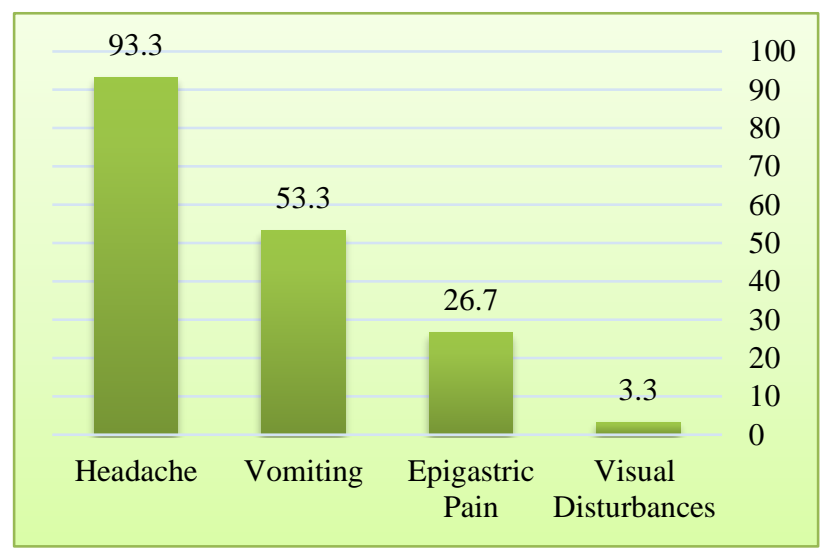

Figure 1: Persistent symptoms

In the present study the common presenting symptoms of PRES were headache $(93.3 \%)$ and vomiting (53. $3 \%$ ). Whereas several studies reported headache and visual disturbances/visual loss to be the common symptoms. , $^{3,8,19-21} \mathrm{We}$ observed epigastric pain in $26.7 \%$ patients and visual disturbances were present in very few patients $(3.3 \%)$. Since MRI is safe to use in pregnancy, its widespread utilization enhances the diagnosis of PRES in eclamptic women with neurological findings (Figure $2 \mathrm{a}-2 \mathrm{~d})$.

In the present study parieto-frontal was the commonly involved area, other less frequently involved areas are temporal, cerebellum periventricular and supraventricular areas. Only one study showed, the obstetric patient demonstrated involvement of the basal ganglia more often, but this was not observed in Fugate et al study.,22 Similar to study by Zeeman GG where they found cerebral oedema in all patients, all our patients also had cerebral oedema. ${ }^{24}$

In the typical form, the abnormalities include both grey and white matter, commonly as hyperintensities in the high frontal, occipital and the posterior parietal lobes bilaterally. In the atypical forms, there can be unilateral or asymmetric pattern of involvement. Unusual locations like brainstem, cerebellum, basal ganglia and selenium, deep white matter in PRES have been documented in literature.

In McKinney et al study atypical patterns like parenchymal or subarachnoid hemorrhages, restricted diffusion and altered brain perfusion in PRES have been reported. ${ }^{2,12}$ In the present study $80 \%$ of MRI showed typical form of PRES lesions and 20\% MRI showed 
atypical form. Many previous studies, observed hemorrhagic lesions in $9-33 \%$ cases of PRES on neuroimaging. ${ }^{2,7,24,25}$ In the present study $3(9.9 \%)$ patients with PRES had hemorrhagic complications. This finding is in consistent with study done Moyama et al. ${ }^{6}$

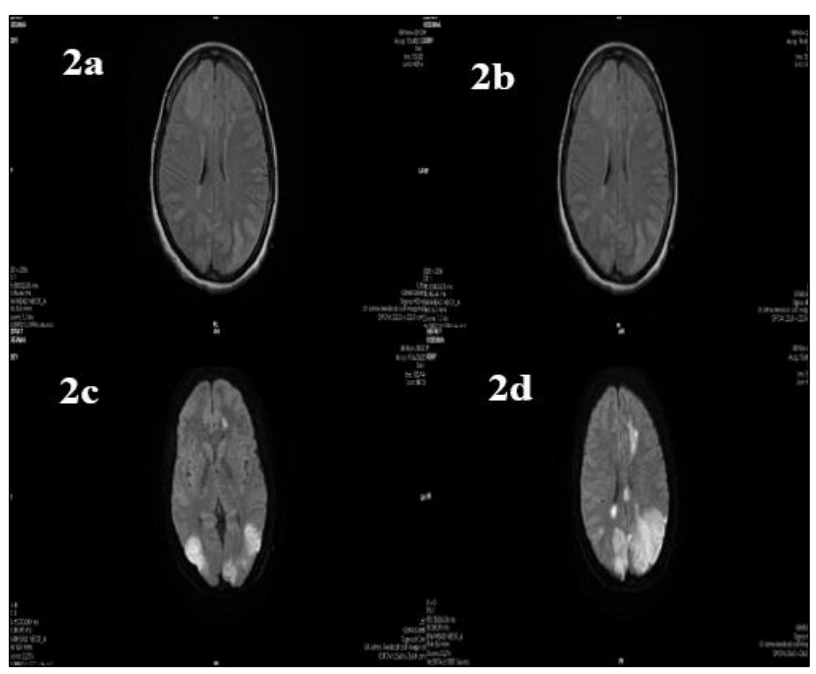

Figure 2a, 2b, 2c and 2d: MRI images of one of the patients showing bilateral hyperintensity on T2weighted images (Figure $2 \mathrm{a}$ and $2 \mathrm{~b}$ ) and fluidattenuated inversion recovery (FLAIR) images (2c and $2 \mathrm{~d}$ ), which is indicative of subcortical oedema.

The pathophysiology of PRES is poorly understood, but it shares same pathophysiological mechanism of eclampsia. $^{12}$ Not all patients with eclampsia exhibit significant hypertension or substantial proteinuria prior to the first seizure. ${ }^{15,26}$ A failed cerebral auto regulation, $\mathrm{BBB}$ disruption, and subsequent vasogenic edema around cerebral arteries and arterioles appears to be the most plausible pathogenetic mechanism responsible for PRES in eclampsia. ${ }^{12,27}$ According to the most accepted theory, an acute rise in blood pressure over a short period of time leads to a failure of normal auto regulatory mechanisms resulting in cerebral hyper perfusion, increased capillary pressure, vasodilatation, and subsequently vasogenicedema. ${ }^{2,28-30}$ This explains that control of hypertension is considered as an important component of PRES management. Antihypertensive treatment using IV labetalol, hydralazine or nifedipine are usually recommended. Labetalol is the drug of choice. ${ }^{31}$ Gradual correction of the hypertension (target systolic 140-150 and diastolic $90-105 \mathrm{~mm} \mathrm{Hg}$ ) is advisable to protect mother and adverse effect on uteroplacental perfusion and foetal status. ${ }^{8}$

Roth $\mathrm{C}$ had reported that PRES can develop without a significant elevation in blood pressure, like eclampsia can occur at blood pressure that that are considered as normal. ${ }^{18,32}$ Mean BP of our patients with PRES $(187 / 110)$ and were treated with IV labetalol, hydralazine and Nifidepine, this results are similar to Brewer J study where as Nelli et al and Wgners $\mathrm{J}$ have reported that the levels of blood pressure elevation were lower (peak SBP $173 \mathrm{~mm} \mathrm{Hg}) .{ }^{14,2,3}$

The control of seizure in eclamptic women is the main step of the treatment and Mgso4 is the drug of choice. Magnesium decreases neuronal excitability, protects endothelium against damage by free radicals, or reduces cerebral perfusion pressure. ${ }^{7,33,34}$ In central nervous system it may also protect the BBB (blood brain barrier) and there by limit cerebral edema formation.

In the peripheral vasculature or cerebral vasculature, it may act as a vasodilator to decrease peripheral resistance. ${ }^{8,33}$ Other antiepileptic medications alone or together with $\mathrm{MgSO}_{4}$, such as diazepam, phenytoin and valproic acid are used for seizure control in patients with recurrent seizures but their use is not approved by all authors because of their side effects. Eclampsia with recurrent seizures were controlled with $\mathrm{MgSO}_{4}(100 \%)$ alone in our study where as Shobhabhomalgi study reported only $67 \%$ responded to $\mathrm{MgSO}_{4}$ and others required additional anticonvulsants to control the seizures.

Corticosteroids can be used to treat hemolysis, elevation of liver enzymes and lowering platelet count that occurs in HELLP syndrome. Theoretically, corticosteroids should reduce vasogenicedema. ${ }^{18}$ Recent study done by Mayama et al showed that patient who received antenatal steroid to enhance lung maturation or for treatment for HELLP revealed faster normalization of central nervous system function in eclamptic patients with PRES. ${ }^{6,19}$ In the present study even though patients received corticosteroids for the treatment or to enhance the lung maturity effect on recovery is not studied.

Globally, eclampsia is one of the leading reasons of maternal morbidity and mortality. ${ }^{7}$ Few studies have reported enhanced maternal deaths in eclampsia associated with PRES. The outcome of pregnant women with PRES was usually reported as favorable, with resolution being rapid and complete after adequate therapy, although permanent damage can persist, and death due to hemorrhage was described..$^{34,35}$

Admission of PRES patients to the ICU is advisable, to allow optimum patient monitoring and prevention of possible complications. In the present study $53.3 \%$ of our patients had eclampsia related complications and $36.7 \%$ required ICU care as compare to study done by Manvi PJ $11 \%$ required ICU care. ${ }^{15}$ Death has been reported in up to $15 \%$ of patients with PRES, but contributing and/or associated factors to the fatal outcomes are unclear. ${ }^{36}$ Martin and Sighai reported that $5-12 \%$ of cases had irreversible brain damage leading to severe neurologic deficits or deaths. ${ }^{37,38}$

Few case reports reported mortality due to haemorrhage in eclamptic women complicated with PRES. ${ }^{39}$ We observed $10 \%$ maternal mortality in the present study 
mainly in patients who had DIC Pulmonary oedema or HELLP syndrome. Perinatal outcome in women with PRES depends on gestational age at delivery. In the present study, preterm deliveries were $49.1 \%$ and perinatal deaths were $20 \%$ and are mainly due to extreme prematurity. These results coincide with study done by Kurdgolu $\mathrm{Z}$ et al $22 \%$ preterm deliveries and $11 \%$ perinatal mortality are reported in Mavani et al study. ${ }^{15}$ Kurdgolu $\mathrm{Z}$ et al and Camara-Limarroy et al reported that infants of mothers with eclampsia complicated with PRES had low 1-minute APGAR score, these findings are similar to the present study. ${ }^{40,41}$ Comparison of other studies with the present study parameter are shown in Table 4.

Table 4: Comparison of other studies with the present study.

\begin{tabular}{|lllll|l|}
\hline Parameters & Present study & Brewer and colleagues & Roth C et al Bembalgi S & Wagner SJ & Fisher N et al \\
\hline Headache & $93.3 \%$ & $87.20 \%$ & $87.50 \%$ & & \\
\hline Visual disturbances & $3.30 \%$ & $4.00 \%$ & $75 \%$ & & \\
\hline MgSO$_{4}$ & $100 \%$ & & $64 \%$ & \\
\hline Perinatal mortality & $20 \%$ & & $27 \%$ & $173 \mathrm{~mm} \mathrm{Hg}$ \\
\hline Blood pressure & $>180 \mathrm{~mm}$ & & & $<48$ hours \\
\hline MRI & Within 72 hours & & $20-25$ hours & 26 years mean \\
\hline Age & 22-30 years & & Post-partum & Post-partum \\
\hline Eclampsia & Ante partum & & & \\
\hline
\end{tabular}

Limitation of the present study is that, it is a retrospective study without any control group.

\section{CONCLUSION}

Incidence of PRES being high, High index of suspicion and early neuroimaging studies could result in early diagnosis. Multidisciplinary approach in management will help to improve the outcome. So, the stage is set, for a prospective study of clinical and neuroradiologic correlates in eclamptic women with clinical signs of PRES and also studies their long-term neurologic outcomes. In patients with PRES a timely intervention with anti-hypertensives, anti-cerebral oedema measures as well as management of other associated symptoms can make this condition truly reversible.

Funding: No funding sources

Conflict of interest: None declared

Ethical approval: The study was approved by the Institutional Ethics Committee

\section{REFERENCES}

1. Hinchey J, Chaves C, Appignani B, Breen J, Pao L, Wang $A$ et al. A reversible posterior leukoencephalopathy syndrome. Engl J Med. 1996;334:494-500.

2. Fugate JE, Rabinstein AA. Posterior reversible encephalopathy syndrome: clinical and radiological manifestations, pathophysiology, and outstanding questions. Lancet Neurol. 2015;14.

3. Sraykov D, Schwab S. Posterior reversible encephalopathy syndrome. J Intensive Care Med. 2012;27:11-24.
4. Lee VH, Wijdicks EF, Manno EM. Clinical spectrum of reversible posterior leukoencephalopathy syndrome. Arch Neurol. 2008;65:205-10.

5. Matsuda H, Sakaguchi K, Shibasaki T. Cerebral edema on MRI in severe preeclamptic women developing eclampsia. J Perinat Med. 2005;33:199205.

6. Mayama M, Uno K, Tano S, Yoshihara M, Ukai M, Kishigami Y, et al. Incidence of posterior reversible encephalopathy syndrome in eclamptic and women with preeclampsia with neurologic symptoms. Am J Obstet Gynecol. 2016;215:239.e1-239.e15.

7. Junewar V, Verma R, Sankhwar PL, Garg RK, Singh MK., Malhotra HS, et al. Neuroimaging features and predictors of outcome in eclamptic encephalopathy: a prospective observational study. Am J Neuroradiol. 2014;35:1728-34.

8. Brewer J, Owens MY, Wallace K. Posterior reversible encephalopathy syndrome in 46 of 47 patients with eclampsia. Am J Obstet Gynecol. 2013;208:68.e1-468.e6.

9. Bembalgi S, Kamate V, Shruthi KR. A Study of eclampsia cases associated with posterior reversible encephalopathy syndrome. J Clin Diagn Res. 2015;9(7).

10. Rodrigo P, Paul EM, Joseph V. Posterior reversible encephalopathy syndrome: a review. Crit Care and Shock.2009;12:135-43.

11. Bartynski WS. Posterior reversible encephalopathy syndrome, part 2: controversies surrounding pathophysiology of vasogenic edema. AJNR Am J Neuroradiol. 2008;29:1043-9.

12. McKinney AM, Short J, Truwit CL. Posterior reversible encephalopathy syndrome: incidence of atypical regions of involvement and imaging findings. AJR Am Roentgenol. 2007;189:904-12. 
13. Nobi PN. Hajong A. Eclampsia in India through the decades. J Obstet Gynaecol Ind. 2016;66S(S1):S1726.

14. Fisher N, Saraf S, Egbert N, Homel P, Stein EG, Minkoff. Clinical correlates of posterior reversible encephalopathy syndrome in pregnancy. J Clin Hypertension. 2016;18(6):522-7.

15. Mavani PJ, Oza HV, Vohra HM. Posterior Reversible Encephalopathy Syndrome (PRES) In pregnancy. Int J Cur Res Rev. 2015;7(20):41.

16. Jamie MN, Shervin E. Late postpartum eclampsia with posterior reversible encephalopathy syndrome. Hospital Physician. 2007;43(6):45-9.

17. Vinod SP, Dhamangaonkar BR, Pattanshetti RC, Patil MM. Posterior reversible encephalopathy syndrome in early postpartum women: a case report. J Clin Diag Res. 2014;8(4):RD01.

18. Chhabra A, Jagtap S. Postpartum seizures with posterior reversible encephalopathy syndrome following cesarean delivery for triplets. J Obstet Anaesth Crit Care. 2014;4(1):50-2.

19. Schwartz RB, Feske SK, Polak JF. Preeclampsiaeclampsia: clinical and neuroradiographic correlates and insights into the pathogenesis of hypertensive encephalopathy. Radiol. 2000;217:371.

20. Demir BC, Ozerkan K, Ozbek SE, Yildirim EN, Ocakoglu G. Comparison of magnesium sulfate and mannitol in treatment of eclamptic women with posterior reversible encephalopathy syndrome. Arch Gynecol Obstet. 2012;286:287-93.

21. Roth C, Ferbert A. Posterior reversible encephalopathy syndrome: long-term follow-up. J Neurol Neurosurg Psychiatry. 2010;81:773-7.

22. Mueller-Mang C, Mang T, Pirker A, Klein K, Prchla C, Prayer D. Posterior reversible encephalopathy syndrome: do predisposing risk factors make a difference in MRI appearance?. Neuroradiol. 2009;51(6):373-83.

23. Wagner SJ, Acquah LA, Lindell EP, Craici IM, Wingo MT, Rose $\mathrm{CH}$, et al. Posterior reversible encephalopathy syndrome and eclampsia: pressing the case for more aggressive blood pressure control. Mayo Clin Proc. 2011;86(9):851-6.

24. Zeeman GG, Cunningham FG. Posterior reversible encephalopathy syndrome in 46 of 47 patients with eclampsia. Am J Obstet Gynecol. 2014;210:378-9.

25. Demirtas O, Gelal F, Vidinli BD, Demirtas LO, Uluc E, Baloglu A. Cranial MR imaging with clinical correlation in preeclampsia and eclampsia. Diagn. Interv Radiol. 2005;11:189-94.

26. Burnett MM, Hess CP, Roberts JP, Bass NM, Douglas VC, Josephson SA. Presentation of reversible posterior leukoencephalopathy syndrome in patients on calcineurin inhibitors. Clin Neurol Neurosurg. 2010;112:886-91.

27. Dahmus MA, Barton JR, Sibai BM. Cerebral imaging in eclampsia: magnetic resonance imaging versus computed tomography. Am J Obstet Gynecol. 1992;167:935-41.
28. Pula JH, Eggenberger E. Posterior reversible encephalopathy syndrome; current opinion. Ophthalmol. 2008;19(6):479-84.

29. Xuan H, Jinfeng X, Zao C, Guoliang L, Hong J. Posterior reversible encephalopathy syndrome with involvement of the cervical cord and medulla: a case report. J Clin Diag Res. 2015;9(1):CD01.

30. Ishikura $K$, Ikeda M, Hamasaki $Y$, Hataya $H$, Nishimura G, Hiramoto R, et al. Nephrotic state as a risk factor for developing posterior reversible encephalopathy syndrome in pediatric patients with nephrotic syndrome. Nephrol Dial Transplant. 2008;23(8):2531-6.

31. Cipolla MJ, Sweet JG, Chan SL. Cerebral vascular adaptation to pregnancy and its role in the neurological complications of eclampsia. J Applied Physiol. 2011;110(2):329-39.

32. American College of Obstetricians and Gynecologists. Emergent therapy for acute-onset, severe hypertension with preeclampsia or eclampsia. ACOG Committee Opinion no. 514. 2011.

33. Euser AG, Cipolla MJ. Magnesium sulfate for the treatment of eclampsia: a brief review. Stroke. 2009;40:1169-75.

34. Narbone MC, Musolino R, Granata F. PRES: posterior or potentially reversible encephalopathy syndrome? Neurol Sci; 2006;27:187-9.

35. Servillo G, Striano P, Striano S, Tortora F, Boccella $\mathrm{P}$, De Robertis E, et al. Posterior reversible encephalopathy syndrome (PRES) in critically ill obstetric patients. Intensive Care Med. 2003;29(12):2323-26.

36. Liman TG, Bohner G, Heuschmann PU, Scheel M, Endres M, Siebert E. Clinical and radiological differences in posterior reversible encephalopathy syndrome between patients with preeclampsiaeclampsia and other predisposing diseases. Eu J Neurol. 2012;19(7):935-43.

37. Hefzy HM, Bartynski WS, Boardman JF, Lacomis D. Hemorrhage in posterior reversible encephalopathy syndrome: imaging and clinical features. AJNR Am J Neuroradiol. 2009;30(7):13719.

38. Martin JN Jr, Owens MY, Keiser SD. Standardized Mississippi protocol treatment of 190 patients with HELLP syndrome: slowing disease progression and preventing new major maternal morbidity. Hypertens Pregnancy. 2012;31:79-90.

39. Sighal AB, Kimberly WT, Schaefer PW, HedleyWhyte ET. Case records of Massachusetts General Hospital. A 36-years-old woman with headache, hypertension, and seizure 2 weeks postpartum. N Engl J Med. 2009;360(11):1126-37.

40. Sargin MA, Tug N, Karadogan FO, Yassa M, Guner D. Posterior reversible encephalopathy syndrome and maternal death in an obstetric patient: case report. Hong Kong J Emerg Med. 2016;23(5):297.

41. Kurdoglu Z, Cetin O, Sayın R, Dirik D, Kurdoglu M, Kolusar1 A, et al. Clinical and perinatal outcomes in eclamptic women with posterior reversible 
encephalopathy syndrome. Arch Gynecol Obstet. 2015;292:1013-8.

42. Camara-Lemarroy CR, Escobedo-Zúñiga N, Villarreal-Garza E, García-Valadez E, GóngoraRivera F, Villarreal-Velázquez HJ. Posterior reversible leukoencephalopathy syndrome (PRES) associated with severe eclampsia: Clinical Biochem Features Pregnancy Hypertens. 2017;7:44-9.
Cite this article as: Karanth S, Gonsalves K, Sheela CN, Mathew R, Sarma GRK, Phillip B et al.

Maternal and perinatal outcome in eclampsia complicated by posterior reversible encephalopathy syndrome; a three years' experience in a tertiary care hospital. Int J Reprod Contracept Obstet Gynecol 2017;6:5044-50. 